\title{
TỔ CHỨC XÃ HộI VÀ SỤ’ CỐ KẾT CộNG ĐỒNG TRONG SỬ THI XƠ ĐĂNG
}

\author{
Lê Ngọc Bính ${ }^{\text {a* }}$ \\ ${ }^{a}$ Khoa Ngũ văn và Văn hóa học, Trường Đại học Đà Lạt, Lâm Đồng, Việt Nam \\ Lịch sử bài báo \\ Nhận ngày 15 tháng 05 năm 2017 \\ Chỉnh sửa ngày 02 tháng 10 năm 2017 | Chấp nhận đăng ngày 09 tháng 10 năm 2017
}

\section{Tóm tắt}

Sử thi Xo Đăng chứa đụng nhiều nội dung nhu lịch sử, xã hội, văn hóa ... của người dân Xo Đăng. Bài viết sẽ làm nổi bật các đặc điểm tổ chức xã hội và sự cố kết cộng đồng bền chạt được phản ánh trong bộ sử thi của dân tộc này.

Từ khóa: Cộng đồng; Dân tộc; Sử thi; Xã hội.

\section{DÃ̃N NHẬP}

Các Hơ m’uan - sử thi Xơ Đăng được giới thiệu gần đây là sản phẩm của Dự án Điều tra, sưu tầm, bảo quản, biên dịch và xuất bản kho tàng sủ thi Tây Nguyên do Trung tâm Khoa học xã hội và nhân văn quốc gia (nay là Viện Hàn lâm Khoa học Xã hội Việt Nam) chủ trì, phối hợp với các tỉnh Tây Nguyên thực hiện từ năm 2001, đã công bố 06/106 tác phẩm sử thi Xơ Đăng sưu tầm được ở Kon Tum. Tuy vậy, so với sử thi các dân tộc bản địa Tây Nguyên thì sử thi Xơ Đăng được tiến hành sưu tầm và nghiên cứu muộn hơn đã đặt ra yêu cầu cần phải có những công trình nghiên cứu về sử thi của dân tộc Xơ Đăng để sử thi dân tộc này tránh khỏi sự mai một, quên lãng. Về nghiên cứu nội dung và nghệ thuật sử thi Xơ Đăng mới chỉ có một vài bài nghiên cứu nhỏ lẻ, mang tính nhận diện, việc sử dụng lý thuyết liên ngành để nghiên cứu bộ sử thi này còn rất hạn chế cho nên nhiều nội dung như văn hóa, lịch sử, xã hội,... còn đang bị bỏ ngỏ. Do vậy sử dụng các phương pháp nghiên cứu liên ngành để nghiên cứu sử thi là việc cần kíp, ở đây là sử dụng liên ngành Văn học - Sử học, Văn học - Văn hóa học, Văn học - Xã hội học, Văn học - Dân tộc học, Văn học - Sinh thái học... để nghiên cứu các tác phẩm sử thi. Bài 
nghiên cứu sử dụng kinh nghiệm của nhiều ngành khoa học để làm nổi bật các vấn đề về tổ chức xã hội và sự cố kết cộng đồng được phản ánh trong sử thi Xơ Đăng.

Khả năng dung chứa của sử thi đối với các biểu hiện đời sống kinh tế, lịch sử, xã hội, văn hóa,... của nhân loại là vô cùng lớn lao. Sử thi Tây Nguyên nói chung, sử thi Xơ Đăng nói riêng cũng chứa đựng những mảng màu lịch sử, xã hội, văn hóa đa dạng, độc đáo của cư dân bản địa ở Tây Nguyên. Với sử thi Xơ Đăng đó là những sinh hoạt kinh tế truyền thống, tổ chức xã hội, cộng đồng và sự cố kết cộng đồng, quan hệ giữa các dân tộc và chiến tranh, những tín ngưỡng, phong tục và lễ hội... Tất cả được nghệ thuật hóa trở nên sinh động, hấp dẫn nhưng vẫn thể hiện được nét chân thực toàn cảnh đời sống của cư dân Xơ Đăng xa xưa. Trong giới hạn của bài nghiên cứu này, chúng tôi chỉ tập trung khai thác các yếu tố như tổ chức xã hội và sự cố kết cộng đồng được thể hiện trong sử thi dân tộc Xơ Đăng.

\section{TỔ CHỨC XÃ HộI TRONG SỦ THI XƠ ĐĂNG}

Đơn vị hành chính cổ truyền của người Tây Nguyên là làng, buôn (Người Êđê gọi là buôn; Người Giarai gọi là polơi; Người Khơmú gọi là kung; Người Cơtu là wel; Người Xơ Đăng, Bana gọi là plây, polây; Người K'Ho, Churu, Mạ gọi là bon,...). Ngoài plây, người Xơ Đăng còn gọi là plê, blê, hlây. Tên làng được đặt theo tên người lập làng, dựa theo những đặc điểm tự nhiên trong vùng hoặc theo một truyền thuyết. Trong sử thi thường nhắc đến làng như một định danh, định vị không gian. Đó là làng của ông Tur Rơ Mu, ông Nhâk Kân, ông Du Teh, ông Gleah, ông Tur Gôk, ông Glang Jri, ông Nur Lao, ông Rang Pơ Ti, Nang Grai, Ling Không, Tur Du... Giữa các làng vừa có mối quan hệ hòa hảo vừa đối địch. Mỗi làng tượng trưng bằng một nhà rông cộng đồng, nơi tổ chức các lễ hội, nơi nam thanh nữ tú tụ tập giao lưu, ca hát, đan lát, dệt vải. Trong làng có nhiều người già có uy tín, được trọng vọng thường đứng ra chủ trì các nghi thức trong lễ hội, tang ma, đám cưới như Tung Brung, Ma Dong, Ma Wăt, Pom Moh, Set Sam Bram, Ling Không, Sor Tơ Mo, Bok Ông Bok Grah, Bok Luông Răng Jrăng, Hơ Drăng Măt Năr, ông Ôông, ông Drun Nun Nut, Bok Riah và thế hệ những người trẻ tuổi như Dăm Duông, Dăm Diă, Dăm Rok, Dăm Gap, Bar Mă, Bia Mă, Brăng Chăm, Brăng Chu, Duông Nâng, Hơ Ne Plêng,... là những người có hay không có quan hệ huyết thống với nhau. Chẳng 
hạn gia đình ông Gleah với nhiều thành viên: Vợ là bà Hla Rơ Kong (trong Dăm Duông trong lốt ông già là bà Jư Rơ Da, Duông đi theo thần Tung Gur là bà Chun Rơ Da Bia Ting Ning), các con Dăm Rok, Dăm Gap, Dăm Diă, Dăm Ri Tang Glang, Bia Mă... và có quan hệ họ hàng với các ông Ma Dong và Ma Wăt (là những ông cậu của Dăm Duông trong Dăm Duông hóa cọp)... Tên gọi tộc người trong sử thi là xứ Hơ Dang (gọi chệch của Xơ Đăng), xứ Mơ Nâm (nhóm tộc người Xơ Đăng) hay xứ Lào, xứ Yuăn (Việt), xứ Nur (tên một tộc người)... Gia đình trong sử thi Xơ Đăng không có những tình tiết con cái chống lại cha mẹ, anh em bất hòa, người trẻ trịch thượng với người già, dân làng chống lại thủ lĩnh... mà:

Phận con cháu phải vâng lời người lớn. Người lớn bảo chúng ta làm thế nào thì phải làm thế nấy. Ông, bà, cha mẹ sinh ra chúng ta, nuôi nấng chúng ta từ bé biết bao khổ cực, lẽ nào chúng ta lại không nghe lời? (Viện Nghiên cứu Văn hóa, 2007, tr. 488).

Trong làng, các thành viên bình đẳng về quyền lợi và nghĩa vụ. Đất đai, núi rừng, sông suối đều thuộc sở hữu chung của công xã, ai cũng được quyền khai phá sản xuất. Đó là chế độ xã hội cộng đồng cuối thời kỳ cộng sản nguyên thủy đang dần tiến lên xã hội có giai cấp. Đã có sự phân chia giàu nghèo, những người giàu thường do lao động mà có, họ là những người có: “Của cải nhiều như lá tre/ Đồ đạc nhiều như lá rừng/ Cồng chiêng nhiều như lá cây đa/ Trâu bò đông như kiến, như mối” (Viện Nghiên cứu Văn hóa, 2009, tr. 1408). Người nghèo thường là mẹ góa con côi, hay mất mùa, đói kém, dịch bệnh mà sinh ra. Biểu hiện rõ nét của xã hội trong sử thi Xơ Đăng là tính tập thể cộng đồng về cư trú, sở hữu lợi ích, tâm linh và văn hóa. Mọi người trong làng ai cũng hiểu rõ trách nhiệm của mình trong việc xây dựng, bảo vệ uy tín của làng. Chủ làng (can plây) nhiều khi được nói đến như là chủ nóc (can rpoong) là người đứng đầu đại diện cho cả làng. Đó là người giàu có, uy tín. Phân công lao động xã hội cũng rất rạch ròi, thường là theo giới tính và tuổi tác. Trẻ em và người già được ưu tiên hơn về công việc, nam làm các việc nặng, nữ chăm nom gia đình và phụ giúp nam giới trong sản xuất:

Người ta chia nhau thành từng nhóm: Nhóm mổ trâu, nhóm mổ bò, nhóm làm thịt heo. Đó là các nhóm công việc của những người đàn ông, con trai. Ngoài ra, còn 
có các nhóm khác, như nhóm thái thân cây chuối để làm thức ăn, nhóm luộc rau hming, nhóm luộc rau diệu... những công việc ấy thuộc về đàn bà, con gái. (Viện Nghiên cứu Văn hóa, 2009, tr. 410).

Trong công việc nương rẫy, Dăm Duông, Dăm Gap, Dăm Diă,... phát đốt, chọc lỗ; Bar Mă, Bia Mah, Brăng Chăm, Brăng Chu,... tra hạt, cùng nhau làm cỏ, bảo vệ và thu hoạch. Dăm Duông đan lát giỏi, Bar Mă biết dệt những tấm vải nhanh và đẹp... Những chàng trai lên rừng đi săn, các cô gái xuống suối hái rau, xúc cá...

Trong sử thi Xơ Đăng xuất hiện các cộng đồng được tổ chức theo một thể chế quân sự, đứng đầu là các thủ lĩnh tài ba. Trong Dăm Duông bị bắt làm tôi tớ là thủ lĩnh Măng Lăng, hay thủ lĩnh Dăm Duông, Tur Gôk trong Dăm Duông làm thủ lĩnh... Đó là những người đứng đầu một đội quân hàng trăm, hàng ngàn người được trang bị "lính áo xanh, áo đỏ, áo trắng” (Viện Nghiên cứu Văn hóa, 2009, tr. 1322). Đó là những người đứng đầu có tài khiên đao, khả năng cầm quân và dụng binh. Việc lập ra các đội quân tinh nhuệ với khiên đao sẵn sàng không nhằm ngoài hai mục đích chính là bảo vệ buôn làng trước sự xâm lăng của các làng khác và đi đánh các làng cướp đất đai, của cải. Đó cũng là một thực tế từng diễn ra ở các làng người Xơ Đăng trước đây.

Nhìn chung từ trước tới nay, làng (buôn, bon, play, plê, trum, sóc...) là kết cấu xã hội điển hình và bền vững nhất của cư dân, đặc biệt là cư dân nông nghiệp. Trong quá trình sinh tồn và phát triển tộc người đã nảy sinh nhu cầu định cư thành từng nhóm, hợp lực để chống chọi với những bất lợi về môi trường tự nhiên và xã hội, đặc biệt là ở vùng Tây Nguyên. Trong quá trình đô thị hóa mạnh mẽ như hiện nay, cần có những chính sách hợp lý để phát triển bền vững vùng Tây Nguyên, trong đó cần bảo tồn hệ thống luật tục, hương ước trong việc quản lý cộng đồng làng buôn ở tất cả các mặt kinh tế, văn hóa, xã hội, bảo vệ đất đai và tài nguyên thiên nhiên...

\section{SỰ CỐ KẾT CộNG ĐỒNG TRONG SỬ THI XƠ ĐĂNG}

Ngô (2007, tr. 213) khẳng định:

Làng trở thành một kết cấu kinh tế, xã hội và văn hóa và mang trong mình nó sức mạnh cố kết cộng đồng rất bền chặt... Tính cộng đồng của làng buôn các tộc người 
Tây Nguyên biểu hiện rất rõ nét và đa dạng, từ đó hình thành tâm lý cộng đồng. Những nền tảng cơ bản để hình thành nên tính cộng đồng, sự cố kết và tâm lý cộng đồng đó là dựa trên sự cộng đồng về cư trú (cộng cư), cộng đồng về sở hữu và lợi ích (cộng lợi), cộng đồng về tâm linh (cộng mệnh), và cộng đồng về văn hóa (cộng cảm).

Như vậy, cộng đồng và sự cố kết cộng đồng dựa trên nền tảng cư trú, sở hữu lợi ích, tâm linh và văn hóa, và theo các luật tục quản lý cộng đồng. Sử thi Xơ Đăng trong chừng mực nhất định phản ánh tính cộng đồng và sự cố kết của nó thông qua các biểu hiện xã hội, lịch sử và văn hóa truyền thống. Như trên đã nói, làng là tổ chức xã hội phổ biến của người Xơ Đăng, và làng trong trường hợp này lại thể hiện cao nhất tính cộng đồng và sự cố kết cộng đồng của nó. Không chỉ vậy, sử thi Xơ Đăng còn tăng cường cấp độ gắn kết cộng đồng thông qua việc mở rộng phạm vi ra nhiều làng, thậm chí nhiều tộc người cách xa nhau có hay không mối quan hệ hòa ái, bình đẳng hoặc có những xung đột chiến tranh với nhau. Tuy vậy, sử thi lại nói nhiều đến cộng đồng trong sự cố kết bền chặt thông qua cư trú, lao động sản xuất, chiến đấu và các lễ hội, phong tục như tục tiếp khách, tục kết nghĩa, tục cưới hỏi... Đó là những hình thức thể hiện cao độ tính cộng đồng và sự gắn kết cộng đồng như là chiếc nôi nuôi dưỡng sức mạnh của buôn làng vượt qua những khó khăn, thử thách trong đời sống.

Việc xây dựng nhân vật anh hùng với tài trí và sức mạnh ngang với thần linh phải luôn nằm trong sự gắn bó mật thiết với cộng đồng.

Tinh thần dân chủ, ý thức tập thể, mối quan hệ cộng đồng gắn bó giữa nhân vật anh hùng với nhân dân, đó là những nét đặc trưng nói lên ý nghĩa xã hội sâu sắc và tính nhân dân mạnh mẽ của các bản sử thi... Vì vậy, tính tập thể, tính cộng đồng rộng lớn là một trong những đặc trưng chính của sử thi các dân tộc, trong đó nổi lên hình tượng tiêu biểu của nhân vật anh hùng. (Võ, 1983, tr. 353, 379).

Sử thi Xơ Đăng nói lên mối quan hệ hữu cơ giữa người anh hùng với cộng đồng, người anh hùng chỉ có sức mạnh để lập những chiến công lao động và quân sự khi sống trong cộng đồng. Họ cho rằng cộng đồng như một rừng cây và nếu rừng nhiều cây cộng đồng đó sẽ vững mạnh (Dăm Duông cưu nàng Bar Mă). Trong cộng đồng đó nhất thiết 
phải có những thủ lĩnh tinh thần để bảo đảm sự thống nhất của buôn làng tránh những xung đột, chia cách. Họ được xem như là chất xúc tác, thứ keo dính kết vô hình gắn bó các thành viên trong tập thể nhiều cá tính ấy. Vì thế, uy tín và tài lực của họ là tiêu chí đánh giá không thể thiếu khi được chọn lựa. Ông chủ làng là cầu nối tình cảm giữa các cá nhân, các gia đình trong cộng đồng, đặt ra cung cách ứng xử. Ngoài ra là người đặt mối quan hệ của làng với các làng lân cận thông qua giao lưu văn hóa, trao đổi hàng hóa; Đặc biệt trở thành đại diện đến với thế giới siêu linh để truyền tải thông điệp của buôn làng tới các thần... Một vấn đề liên quan đó là lãnh địa cư trú của cộng đồng, đất dựng làng được chọn lựa kỹ lưỡng. Đó phải là nơi thuận lợi về nguồn nước và đất canh tác: “Trong việc chọn đất dựng làng, việc quan trọng nhất là tìm nơi thuận tiện có nguồn nước tốt” (Đặng, Cầm, Trần, Lê, \& Ngô, 1981, tr. 190), trong đó:

Các gia đình, dù là gia đình lớn hay gia đình nhỏ, dù là theo huyết thống mẫu hệ hay phụ hệ, cùng sống trong một buôn làng... Số lượng các gia đình nhiều hay ít là tùy thuộc vào điều kiện môi trường và đất đai canh tác, làng buôn lớn có tới hàng trăm gia đình, nhỏ cũng gồm hàng chục gia đình. (Ngô, 2007, tr. 213).

Cộng đồng trong sử thi Xơ Đăng là các làng với nhiều gia đình sống trong nhiều nóc nhà:

Chẳng mấy chốc ngôi làng ông Glaeh xuất hiện. Đó là một ngôi làng đông dân, có tới 18 ngôi nhà rông. Đấy là những ngôi nhà rông to cao, chưa kể các nhà rông nhỏ và thấp. Ví dù tính hết cả nhà rông nhỏ thì còn nhiều hơn thế nữa. (Viện Nghiên cứu Văn hóa, 2009, tr. 1413).

Các cá nhân trong cộng đồng ấy bình đẳng với nhau, được nhắc đến nhiều nhất là các già làng có vai trò đặc biệt quan trọng trong việc hoạch định các công việc của làng như Bok Glaeh, Nhâk Kân, Glang Jri... "Những thành viên trong một làng hoàn toàn bình đẳng với nhau, được cố kết bởi một tinh thần cộng đồng làng xóm thống nhất, dựa trên một tập quán pháp duy nhất” (Đặng \& ctg., 1981, tr. 191). Do đó ai cũng thể hiện cao độ quyền lợi và trách nhiệm của bản thân, người già trong làng có quyền năng áp dụng các luật tục dựa trên sự tự nguyện của các cá nhân trong làng. Từ đó có thể thấy tinh thần đoàn kết gắn bó mật thiết mà Ngô (2007) gọi là “mật tập” (nêu cao ý nghĩa của cư trú 
ảnh hưởng đến tính thống nhất cộng đồng). Đó cũng là tiền đề cho những ứng xử đẹp đẽ: "Giữa các gia đình trong công xã, dù là thân thuộc hay không thân thuộc, có sự tương trợ về mọi phương diện. Không một ai bị bỏ đói khi kho thóc của người khác còn đầy” (Đặng \& ctg., 1981, tr. 43). Người anh hùng Dăm Duông chia sẻ và đùm bọc người nghèo, ai không có áo vợ chồng Duông cho áo mặc, ai hết cơm ăn Duông cho gạo.

Xã hội Xơ Đăng trước đây, hình thức công xã là phổ biến. Đất đai, rừng rú, sông ngòi đều thuộc về mọi người và có quyền sử dụng ngang nhau. Tuy nhiên, ai khai phá người đó được hưởng và có quyền thừa kế, đổi bán nhưng phải với những người trong làng. Song nhiều khi vẫn có sự tranh chấp. Chẳng hạn trong Duông đi theo thần Tung Gur, khi Duông phát rẫy rộng, Duông Nâng đã có ý tranh chấp nhưng bị dân làng phản đối vì rừng là tài sản chung và người nào có sức lao động, ai siêng năng biến rừng thành rẫy lúa tốt thì xứng đáng được hưởng, nên trong cộng đồng Xơ Đăng mọi người lên án thói lười biếng, không làm mà cứ đòi hưởng lợi, trong lao động đòi hỏi có sự cống hiến ngang bằng. Sử thi miêu tả cảnh lao động cộng đồng. Khi thì cả đoàn người lên rừng hái rau, săn bắn, xuống suối đánh cá; Khi lên núi phát rẫy trỉa lúa, và khi rẫy lúa vàng óng mọi người lại tấp nập thu hoạch mùa màng. Các thành viên đều có ý thức tuyệt đối về trách phận công dân của mình trong buôn làng. Ai có kinh nghiệm, biết điều hay lẽ phải thì truyền dạy cho người khác, người ta khuyến khích sự ham học hỏi, bài trừ tính ỉ lại nên mỗi khi ngả bóng về chiều, người già và trẻ con ngồi lại để truyền nối kinh nghiệm sản xuất. Khi ai đó săn được con thú lớn, con vật được mổ xẻ và chia đều cho từng bếp; Lúa nhà này đầy kho cũng không để người thiếu gạo phải đói.

Người Xơ Đăng quan niệm mình là con cháu của thần linh. Đó là con cháu của Tơ Ro, thần sấm sét, vị thần giúp sức cho cả cộng đồng trong sản xuất, chiến đấu. Do vậy, người ta quan niệm "tất cả do thần (giàng - yang, kia, kiếc)", sống chết hay giàu nghèo là ý của thần nên con người phó mặc tuyệt đối của cho các đấng siêu linh. Trong sử thi Xơ Đăng, cái quan niệm “chúng ta là con cháu của thần” trở nên phổ biến, chi phối hành động và ứng xử của con người. Thần linh được xem là "pháp luật lương tâm" uốn nắn đời sống của cả dân làng, ngăn cấm những việc làm trái ngược đạo đức, phong tục. Nhãn quan thần thoại thấm đẫm cuộc sống của con người nơi đây. Việc sử thi xây dựng một hệ thống các nhân vật thần linh như là một cách giãi bày về sự gắn bó giữa đời 
thực và tâm linh, vừa thực vừa ảo nhưng mật thiết. Các thần đi vào đời sống con người một cách tự nhiên, con người cũng thường xuyên thâm nhập vào thế giới của các thần, chứng tỏ một cộng đồng hòa kết: Người - Thần:

Những thành viên trong cộng đồng có quan hệ với nhau không chỉ trong cuộc sống thực tại nhưng ngắn ngủi, mà cả trong cuộc sống hư ảo nhưng linh thiêng trước thần linh ngay trong khi còn sống và kéo dài cả sau khi chết. Đó là cộng đồng của những người đương sống, đã chết và cả những người sắp sinh ra, một tập hợp những người một lòng mong muốn cho cộng đồng mình lớn mạnh, trường tồn. Điều đáng sợ của mỗi một thành viên chưa phải là cái chết vì nghĩa vụ, mà là sự ruồng bỏ của cộng đồng. Tội nặng nhất chưa phải là tội chết mà là tội bị đuổi ra khỏi cộng đồng. (Đặng \& ctg., 1981, tr. 192).

Như vậy một cá thể phải sống trong cộng đồng mới trở thành một con người thực thụ, bị đuổi ra khỏi cộng đồng là sự sỉ nhục vô cùng ghê gớm. Tuy nhiên người ta vẫn có quyền bứt thoát ra khỏi cộng đồng khi có nhu cầu đi sống với một làng khác được sự đồng ý của cả hai làng. Nhưng cái cốt lõi vẫn là "tâm thức cộng đồng”, muốn hay không thì ở một làng xa xôi nào đó, họ cũng phải bám rễ ở cộng đồng, sống với bản mệnh mới. Con người chết đi về với thế giới thần, trong tâm thức ở thế giới ấy họ vẫn tiếp tục sống, lao động, sản xuất và chiến đấu nên người ở trần thế vẫn chưa dứt hẳn mối quan hệ mà luôn giữ sợi dây với những người quá cố. Điều này dẫn đến một tục lệ phổ biến không chỉ ở người Xơ Đăng mà nhiều dân tộc ở Tây Nguyên, đó là tục chia của, thậm chí hiến sinh nô lệ. Tục lễ này trở thành một hủ tục và đang dần mất đi trong đời sống của các cư dân.

Tính cộng đồng và cố kết cộng đồng còn thể hiện trong đời sống văn hóa vô cùng phong phú, đa dạng của người Xơ Đăng. Sử thi phản ánh nhiều lễ hội, phong tục độc đáo. Đó là các lễ hội cộng đồng như lễ hội mừng năm mới, lễ cúng máng nước, lễ ăn cơm mới, lễ mừng nhà rông, lễ cưới... tất cả đều có sự tham gia đông đảo của cộng đồng không phân định giới hạn không gian, thời gian. Tất cả các thành viên như những vật thể kim loại bị hút bởi từ trường nam châm cùng hội tụ về các lễ hội ăn năm uống tháng đầy sắc màu văn hóa. Tất cả mọi người từ trên mọi ngả đường nẻo dặm cùng đến "góp gạo thổi com chung”. Cộng đồng ấy rộng lớn bao la được cố kết bởi một truyền thống hiếu khách 
từ bao đời nên mỗi khi chiêng trống một làng nổi lên họ lại đổ về để chia buồn khi làng có tin xấu hay vui chơi, ca hát, nhảy múa khi làng mở hội. Và ở đó, trai gái đến với nhau bằng những câu tình tứ, các cụ già lụ khụ tiếng ho cùng kể chuyện cha ông xưa truyền lại... Hội hè trở thành một hình thức cộng cảm vô cùng hữu hiệu.

Nhà rông là nơi hội đủ các yếu tố văn hóa cộng đồng, ở đó thường xuyên diễn ra những sinh hoạt văn hóa, văn nghệ: “Trai gái làng bok Glaeh rất đông. Đêm đêm tụ tập tại nhà rông, đốt lửa ca hát và múa thật nhộn nhịp” (Viện Nghiên cứu Văn hóa, 2006, tr. 464). Đó là nơi hội tụ truyền thống, sức mạnh, bản lĩnh của cả làng buôn. Mỗi làng đều có một nóc nhà rông to nhất, là nhà chung của cả làng. Ở đó, mỗi khi có sự việc, già làng thường đánh trống, chiêng kêu gọi họp mặt:

Già làng lên nhà rông đánh một hồi trống, đó là cái trống từ đời xưa để lại đến bây giờ, thường chỉ đánh nó mỗi khi cần gọi dân làng đi trong rẫy, trong rừng xa gần cần phải về gấp. Khi nghe tiếng trống ấy, bất cứ ai ở đâu, đang làm việc gì cũng phải bỏ hết và lập tức về nhà ngay vì họ sợ có việc nguy cấp xảy ra. (Viện Nghiên cứu Văn hóa, 2009, tr. 1274).

Nhà rông trở thành một nét đẹp văn hóa bởi nó hội đủ các yếu tố từ ngàn xưa để lại, từ kết cấu công trình đến không gian nhà rông như là một tổng thể văn hóa cộng đồng. Ở đây cũng cần phải nói thêm, có nhiều tộc người không có nhà rông nhưng vẫn thể hiện được tính cố kết cộng đồng. Thay bằng nhà rông họ có các vật chất tượng trưng chẳng hạn như nhà dài, cây nêu của cả làng, hay chỉ cần một cột đâm trâu... Vai trò của nhà rông là vô cùng quan trọng khi khẳng định cộng đồng đó gắn kết đến mức nào, nhất là một cộng đồng được quân sự hóa, luôn trong tình trạng đối phó với các thế lực thù địch. Ngoài ra, những mái nhà rông cao vút trong đó chất chứa nhiều linh khí (cồng chiêng, gươm quý, ché cổ...) là tiêu chí để nói lên sự giàu có hay thành tích lịch sử của buôn làng ấy. Nếu trong làng có nhiều nhà rông thì nhà rông của làng phải lớn nhất và được gọi là rông yang (Nguyễn, 2007, tr. 241). Dù là nhà rông truyền thống hay các nhà rông văn hóa (mới được xây dựng gần đây) thì cũng đều biểu hiện tính chất cố kết cộng đồng của nó, đó là nơi 
Tiến hành các lễ thức tôn giáo, chỗ hội họp của cả làng... là nơi tập trung thường trực của các trai tráng trong làng với những vũ khí sẵn sàng để luôn ứng phó với tình trạng chiến tranh..., tiện việc huy động trai tráng vào các việc công cộng của làng xóm. Tổ chức các buổi vui chơi giải trí hoặc đan lát..., cho phép trai làng khác đến tìm hiểu con gái làng. (Đặng \& ctg., 1981, tr. 189).

Sống trong một cộng đồng có truyền thống gắn bó mật thiết, thế hệ này đi qua, thế hệ khác nối tiếp. Thế hệ con cháu phải biết quý trọng những tinh hoa mà cha ông họ đã dày công vun đúc, từ đó kế thừa và phát huy nó. Lời ông Bok Glaih nói với ông Tur Rơ Mur:

Chúng ta già yếu rồi, có con cái phải nhờ chứ ông. Chúng nó sẽ là người tiếp tục làm việc thay thế chúng ta. Nếu chúng nó có sức khỏe, có chí làm ăn thì tất nhiên chúng nó phải thay thế chúng ta làm việc nuôi sống gia đình. (Viện Nghiên cứu Văn hóa, 2006, tr. 916).

Thế hệ trẻ không ngừng tiếp thu những vốn sống của cha ông truyền lại: "Người già có vốn sống cho nên họ biết rõ, mới dạy bảo con cái, cho chúng mình, đứa nào khôn thì nhận lấy" (Viện Nghiên cứu Văn hóa, 2006, tr. 917). Trong đời thực, người dân Xơ Đăng rất quý trẻ em, Đặng và ctg. (1981, tr. 210) cho rằng: "Người dân Xơ Đăng rất quý trẻ con. Mơ ước của họ vẫn là con đàn cháu đống”. Ngoài ra, con trẻ cũng phải biết yêu thương, quý trọng người già. Trong lốt ông già, Dăm Duông đã chỉ dạy cho những người trẻ tuổi cách ứng xử với những bậc cao niên theo kiểu "yêu trẻ trẻ đến nhà, kính già già để tuổi cho" của người Kinh:

Xưa nay, con người ta sống ở buôn làng, nếu không có người già chỉ dẫn thì bọn trẻ có biết làm rẫy trồng lúa, trồng bắp không? Phải có người già dạy bảo lũ trẻ mới biết làm ăn, biết làm nhiều việc này, việc nọ. Tại sao lại chê người già? Chính người già sinh ra trẻ nhỏ. Từ nhỏ rồi lớn lên và già nua. Trước là trẻ, sau rồi cũng già như nhau. Thế sao lại khinh thường, ghê tởm người già? Chính lũ cháu cũng từ người già mà sinh ra. (Viện Nghiên cứu Văn hóa, 2007, tr. 813-814). 
Khi trưởng thành, con cái phải biết lao động và làm chủ gia đình, làng buôn. Hạt lúa không phải tự dưng mà có, phải làm lụng để đảm bảo cho cuộc sống đầy đủ. Người giàu cũng phải “đổ mồ hôi, sôi nước mắt” mới được sung túc như thế:

Những người giàu có, sung sướng đâu phải tự dưng mà có. Ai cũng phải chịu cực chịu khổ, phải đổ mồ hôi, phải ra nước mắt, phải chịu vất vả Yang mới thương, mới ban cho ta của cải. Chúng ta luôn làm điều tốt, người tốt phải biết thương yêu, giúp đỡ mọi người. (Viện Nghiên cứu Văn hóa, 2007, tr. 464).

Do đó phải chăm chỉ làm việc, cần cù, siêng năng và không ngừng học hỏi, trau dồi kinh nghiệm trong lao động sản xuất. Sống chết hay giàu nghèo là do Yang định đoạt, nhưng muốn được Yang phù hộ con người phải sống có chuẩn mực đạo đức, ứng xử hòa nhã, yêu thương, giúp đỡ mọi người.

Trong cộng đồng ấy, họ đặt ra những tập quán pháp để bình ổn xã hội cũng như quy định ý thức, quyền và nghĩa vụ của cá nhân đối với cộng đồng. Nhưng trên cái nền cộng đồng cộng cảm, tình yêu thương giữa con người với nhau luôn được đề cao và coi trọng:

Nhờ có tình yêu thương giữa con người nên mới có được sự yên bình. Nếu chúng ta kình địch nhau, ghét bỏ nhau thì làm sao mà có được sự yên bình. Không được bình yên thì làm sao có hạnh phúc sung sướng. (Viện Nghiên cứu Văn hóa, 2009, tr. 676).

Kịch liệt lên án thói kiêu căng, khinh thường mọi người:

Thấy người ta nghèo thì phải rủ lòng thương, đó mới là cao đẹp, ai ai cũng coi trọng... Tại sao lại khinh thường người ta và tự cao tự đại. Tính tự cao là xấu... Trước hết phải làm ăn đàng hoàng tử tế. Thứ hai phải làm việc cần cù siêng năng. Thứ ba, phải đối xử tốt với các anh em, bà con... (Viện Nghiên cứu Văn hóa, 2009 , tr. 464).

Và như thế con người luôn phải yêu thương đùm bọc, giúp đỡ lẫn nhau, bênh vực những người nghèo khổ, những người có hoàn cảnh khó khăn. Có như vậy mới mong 
được thần linh phù hộ, người khác yêu mến. Những người mắc sai trái cũng có thể được tha thứ nếu họ biết thay đổi mình, cố gắng vươn lên hoàn thiện bản thân bởi "sông có khúc, người có lúc" và người ta "đánh kẻ chạy đi, ai đánh người chạy lại”, phải sống vị tha và độ lượng: "Con người ta phải biết điều. Hôm nay họ sai trái, mai kia họ thành tốt, biết đâu ta lại mắc sai lầm...” (Viện Nghiên cứu Văn hóa, 2006, tr. 242-243).

Như vậy cộng đồng và sự cố kết cộng đồng trong sử thi Xơ Đăng là một biểu hiện của lịch sử xã hội ở người dân Xơ Đăng xưa. Sử thi không bê nguyên hiện thực lịch sử xã hội mà đã nghệ thuật hóa hiện thực ấy. Điều này đã được Morfologija (2003) đề cập đến, đó là mối quan hệ giữa thực tại văn hóa (cultural reality) và sự thể hiện thực tại ấy trong văn học dân gian không chỉ có một cách thức phản ánh trực tiếp mà còn cả sự chiêm nghiệm và đảo nghịch đối với thực tại. Nghiên cứu của Morfologija $(2003$, tr. 828$)$ cũng chỉ ra rằng "Hiển nhiên là có phản ánh những quan niệm dân gian nhưng không phải bao giờ cũng là bản thân những quan niệm đó trong nghĩa đen của từ này”. Cho nên để giải thích nguồn gốc của truyện cổ tích hay sử thi cần phải nghiên cứu cả hai loại tư liệu trực tiếp (thần thoại hay tư duy sơ khai của những dân tộc tiền giai cấp) và tư liệu gián tiếp (thần thoại của những dân tộc cổ xưa có văn hóa). Các thể loại Folklore trong đó có sử thi "không phải như một cái gì đó tách rời kinh tế và chế độ xã hội mà là như một cái gì đó phát sinh từ nền kinh tế và chế độ xã hội đó” (Morfologija, 2003, tr. 832). Cho nên ở Tây Nguyên đã lưu truyền lại loại sử thi cổ sơ, loại sử thi đặc trưng cho các dân tộc ở giai đoạn tiền giai cấp và nhà nước bên cạnh loại sử thi cổ đại (cách phân loại này theo tiêu chí lịch sử - xã hội bên cạnh cách phân loại theo tiêu chí dựa vào chức năng, nhiệm vụ của nhân vật trung tâm của sử thi thành sử thi sáng thế và sử thi thiết chế).

Cộng đồng trong sử thi Xơ Đăng là những buôn làng với nhiều nhà rông, trong đó con người sống với nhau bình đẳng được cố kết chặt chẽ. Sự gắn kết đó xuất phát từ truyền thống sản xuất, chiến đấu yêu cầu mọi người phải đứng lại với nhau, sát cánh bên nhau cùng đoàn kết để có thể sinh tồn và chống chọi nổi với những thiên tai, địch họa. Trong quá trình sản xuất và chiến đấu ấy, họ đã sáng tạo nên những giá trị tinh thần phong phú, trong đó có sử thi, một bộ phận đặc biệt của Folklore. Quá trình sáng tạo và tiếp nhận sử thi cũng phụ thuộc vào sự tồn tại của tổ chức xã hội và sự cố kết cộng đồng, bởi vì đặc trưng của văn học dân gian là những sáng tác tập thể, được truyền miệng và mang 
tính hiện thực nên để bảo tồn và phát huy giá trị của sử thi vùng Tây Nguyên, để nó "được sống" thì cần phản bảo tồn các không gian văn hóa cộng đồng, trong đó phải phát huy vai trò của các tổ chức làng truyền thống và sự cố kết bền chặt, thấu hiểu giữa các thế hệ trong cộng đồng ấy, có như vậy con cháu mai sau mới còn được trực mục sở thị một loại hình diễn xướng dân gian độc đáo có một không hai ở Tây Nguyên, Việt Nam.

\section{KẾT LUẬN}

Xuất phát từ nhu cầu sẻ chia trong cuộc sống, người dân Xơ Đăng đã hình thành các tổ chức làng cùng cư trú trên một lãnh địa riêng có ranh giới rõ ràng, cùng cộng cư và đặt ra những quy tắc ứng xử, những luật tục quản lý xã hội trên cơ sở công bằng về lợi ích và tâm lý, từ đó sinh ra sự gắn bó về tâm linh và văn hóa. Cũng vậy, để tăng cường sức mạnh trong sản xuất và chiến đấu, các làng kề cận tìm đến với nhau để gia cố thêm tình hữu nghị đoàn kết, dần mở rộng phạm vi cộng đồng "phát triển lên thành xã hội cộng đồng rộng lớn hơn trên đường tiến lên hình thành dân tộc trong đại gia đình dân tộc Việt Nam" (Võ, 1983, tr. 354). Điều đó thật ý nghĩa đối với quá khứ đã đi qua, hiện tại và tương lai đang rộng mở. Sức mạnh của khối đoàn kết cộng đồng đã trở thành một khối thành trì vững chắc để con người nơi đây vượt qua những mãnh lực từ bên ngoài, nhất là trong hai cuộc kháng chiến chống Pháp, Mỹ. Hiện tại cần phát huy sâu rộng hơn sức mạnh ấy để chắc chắn cho sự phát triển bền vững trên mảnh đất Tây Nguyên nói riêng, cho cả khối đoàn kết dân tộc Việt Nam nói chung. Tóm lại xã hội Tây Nguyên, mà đơn vị cơ sở của nó là buôn, plây, là xã hội trong đó tất cả mọi người là một, một người cũng như tất cả. Hân hoan, đau khổ, giận hờn của một người là của tất cả. Trong nội bộ nói chung không có đối lập, không có giằng xé, không có bi kịch (Phan, 2001, tr. 104-105).

\section{TÀI LIỆU THAM KHẢO}

Đặng, N. V., Cầm, T., Trần, M. C., Lê, D. Đ., \& Ngô, V. B. (1981). Các dân tộc tỉnh Gia Lai - Công Tum. Hà Nội, Việt Nam: NXB. Khoa học Xã hội.

Morfologija, S. (2003). Tuyển tập V.IA. Propp (Tập I). Hà Nội, Việt Nam: NXB. Văn hóa Dân tộc.

Ngô, Đ. T. (2007). Nhũng mảng màu văn hóa Tây Nguyên. TP. Hồ Chí Minh, Việt Nam: NXB. Trẻ. 
Nguyễn, T. K. V. (2007). Đến với lịch sủ - văn hóa Bắc Tây Nguyên. Đà Nẵng, Việt Nam: NXB. Đà Nẵng.

Phan, Đ. N. (2001). Nghiên cưu sử thi Việt Nam. Hà Nội, Việt Nam: NXB. Khoa học Xã hội.

Võ, Q. N. (1983). Văn học dân gian các dân tộc ít người ở Việt Nam. Hà Nội, Việt Nam: NXB. Đại học và Trung học Chuyên nghiệp.

Viện Nghiên cứu Văn hóa. (2006). Kho tàng sủ thi Tây Nguyên - Sư thi Xo Đăng. Hà Nội, Việt Nam: NXB. Khoa học Xã hội.

Viện Nghiên cứu Văn hóa. (2007). Kho tàng sử thi Tây Nguyên - Sủ thi Xo Đăng. Hà Nội, Việt Nam: NXB. Khoa học Xã hội.

Viện Nghiên cứu Văn hóa. (2009). Tổng tập văn học dân gian các dân tộc thiểu số Việt Nam (Tập 8 - Sử thi Xo Đăng). Hà Nội, Việt Nam: NXB. Khoa học Xã hội.

\title{
SOCIAL ORGANIZATION AND COMMUNITY COHESION IN XO DANG EPIC
}

\author{
Le Ngoc Binh ${ }^{\mathrm{a}^{*}}$ \\ ${ }^{a}$ The Faculty of Literature and Cultural Studies, Dalat University, Lamdong, Vietnam \\ *Corresponding author: Email: binhln@dlu.edu.vn \\ Article history \\ Received: May $15^{\text {th }}, 2017$ \\ Received in revised form: October 02 ${ }^{\text {nd }}, 2017$ | Accepted: October 09 ${ }^{\text {th }}, 2017$

\begin{abstract}
The Xo Dang epic contains a lot of content such as history, society, culture, etc of the Xo Dang people. This article will highlight the social organization characteristics and solid community cohesion reflected in the epics of this ethnic group.
\end{abstract}

Keywords: Community; Epic; Ethnic; Society. 